\title{
Pleural Effusion in Children: How often do we suspect Tubercular origin?
}

\author{
Shrestha PN¹, Rayamajhi A ${ }^{2}$
}

${ }^{1}$ Dr. Pun Narayan Shrestha, MBBS. MD, Assistant Professor, ${ }^{2}$ Dr. Ajit Rayamajhi, MBBS. MD. Associate Professor. Both from the Department of Paediatrics, Kanti Children's Hospital, Maharajgunj, Kathmandu. Affiliated to National Academy of Medical Sciences (NAMS).

Address of correspondence: E-mail: shrestha-pn@hotmail.com

\begin{abstract}
Introduction: Pleural effusion is a common problem in children; mostly due to common causes like pyogenic or tubercular infections. Different studies have showed that about $30 \%-60 \%$ of pleural effusion have resulted into formation of empyema. Method: This was an observational study done in children aged 3 months to 14 years with a diagnosis of pleural effusion admitted at Kanti Children's Hospital, Maharajgunj from August 2009 to March 2010. The aim of the study was done to find out different modalities of treatment for the same and their outcome. A detailed clinical history and physical examination, was done in all children. Chest $x$-ray, laboratory reports and treatment were recorded and all patients followed up until death or discharge. Any change of management was also noted. Pleural effusion caused by nephritic syndrome or congestive cardiac failure were excluded from the study. Results: During the study period of eight months, 64 patients were admitted with the diagnosis of pleural effusion. Boys to girls ratio was 2:1. Right-sided pleural effusions were more common than left sided pleural effusions ( $53 \%$ vs. $37 \%)$. Most of patients improved with parental antibiotics along with chest tube drainage (62\%). One in three patients $(31 \%)$ received anti-tubercular drugs. Three patients $(4.6 \%)$ were referred to surgeon for decortications and one patient $(1.6 \%)$ died. Conclusion: Though chest tube drainage with parental antibiotics was the mainstay of treatment of pleural effusion, however one-third of patients also received anti- tubercular drugs.
\end{abstract}

Key words: Pleural effusion, pyogenic, decortication, adenosine deaminase (ADA).

\section{Introduction}

$\mathrm{P}$ leural effusion is defined as collection of fluid in the pleural cavity. It may be transudative or exudative. Exudative pleural effusion may be caused by bacterial or tubercular infection, malignancy etc. The term empyema is used to describe the presence of pus in the pleural cavity. It is usually caused by bacterial pneumonia and tuberculosis ${ }^{1,2}$. Different studies have showed that about $30 \%-60 \%$ of pleural effusion have resulted into formation of empyema ${ }^{3,4,5}$. Because of the high incidence of pneumonia in children under 5 year (90/1000) in Nepal, empyema thoracis can be a common problem ${ }^{6}$. In children empyema thoracis accounts for $8.6 \%$ of hospital admission for lower respiratory infections and about $2 \%$ total hospital admissions in developing countries ${ }^{7}$. The management of empyema is parental antibiotics and intercostal chest tube drainage. In some cases decortication may be needed. Tubercular pleural effusion is also a common problem in developing countries.

\section{Material and Method}

This hospital based observational study was done in the department of medicine of Kanti Children's Hospital, Maharajgunj fromAugust 2009 to March 2010. All children aged 3 month to 14 years who were diagnosed to have pleural effusion on the basis of clinical, radiological and laboratory reports of diagnostic tapping were enrolled in the study. Clinical history, physical examination, x-ray chest, laboratory reports and treatment received were recorded in a standard prorforma. The effusion caused 
by noninfectious origin like nephritic syndrome and congestive cardiac failure were excluded from the study. A member of the research team followed the patients every day until death or discharge.

\section{Results}

During the study period (August 2009 to March 2010), total admission in Kanti Children's Hospital was 6334 out of which 1004(15.8\%) cases were of pneumonia. Among admitted pneumonia cases, 64 patients $(6.3 \%)$ developed pleural effusion. The male to female ratio was $2: 1$ and most of the patients $(46 \%)$ were found in the age group of 5-10 years (Table1). The youngest age was a three months old infant with pleural effusion. The most common symptoms on admission were fever $(90 \%)$, dyspnoea $(82 \%)$, cough $(75 \%)$ and chest pain (20\%). Right sided plural effusion was about $53 \%$ and bilateral effusion was $9.4 \%$ (Table 2 ).

Table 1: Showing age and sex distribution of the study population.

\begin{tabular}{|l|c|c|c|}
\hline Age group & Male & Female & Total $(\mathbf{n = 6 4})$ \\
\hline$<$ I year & 3 & 1 & 4 \\
\hline$>1-5$ & 2 & 7 & 9 \\
\hline$<5-10$ & 24 & 8 & 32 \\
\hline$>10$ & 14 & 5 & 19 \\
\hline Total & $\mathbf{4 3 ( 6 7 . 2 \% )}$ & $\mathbf{2 1 ( 3 2 . 8 \% )}$ & $\mathbf{6 4}(\mathbf{1 0 0} \%)$ \\
\hline
\end{tabular}

Table 2: Showing the clinical features of study cases.

\begin{tabular}{|l|c|c|}
\hline Clinical features & $\begin{array}{c}\text { No. of patients } \\
\text { (N=64) }\end{array}$ & Percentage (\%) \\
\hline Fever & 58 & 90 \\
\hline Dysponea & 52 & 82 \\
\hline Cough & 40 & 75 \\
\hline Chest pain & 13 & 20 \\
\hline Right effusion & 34 & 53.1 \\
\hline Left effusion & 24 & 37.5 \\
\hline Bilateral effusion & 6 & 9.4 \\
\hline
\end{tabular}

Table 3: Showing duration of hospital stay of the study patients.

\begin{tabular}{|l|c|c|}
\hline Duration & No of patients & Percentage \\
\hline Up to 1 week & 12 & $18 \%$ \\
\hline $1-2$ Weeks & 36 & $56 \%$ \\
\hline$>2$ Weeks & 16 & $26 \%$ \\
\hline
\end{tabular}

About half ( $56 \%$ ) of the total patients were admitted for 1-2 weeks in hospital and $26 \%$ patient remained more than 2 weeks in the Hospital (Table 3). The median duration of hospital stay was 12 days with range of 4-45 days.
Table 4: Showing treatment modalities and outcome in patients admitted with pleural effusion.

\begin{tabular}{|l|c|c|}
\hline Treatment & $\begin{array}{c}\text { No of patients } \\
(\mathbf{n = 6 4 )}\end{array}$ & $\begin{array}{c}\text { Percentage } \\
(\mathbf{\%})\end{array}$ \\
\hline Antibiotics only & 16 & 25 \\
\hline $\begin{array}{l}\text { Antibiotics with chest } \\
\text { tube drainage }\end{array}$ & 24 & 37.5 \\
\hline $\begin{array}{l}\text { Antibiotic with ATT \& } \\
\text { chest tube }\end{array}$ & 14 & 21.8 \\
\hline Antibiotic with ATT & 6 & 9.3 \\
\hline Refer for decortications & 3 & 4.6 \\
\hline Death & 1 & 1.5 \\
\hline Total & $\mathbf{6 4}$ & $\mathbf{1 0 0}$ \\
\hline
\end{tabular}

All of the children were initially treated with parental antibiotics. On admission the patients were either treated with ampicillin-cloxacillin $(50 \%)$ or flucloxacillin (45\%) with or without cefotaxime. If the patients showed no improvement with the above antibiotics, vancomycin $(18.2 \%)$ with or without ceftazidime was added. About half of the total $(59.3 \%)$ patients were put on chest tube drainage and twenty (31\%) patients received antitubercular treatment (ATT). Two patients received ATT on the basis of positive Adenosine deaminase (ADA) test $(10 \%)$ in pleural fluid and four patients received on the basis of positive Mantoux test (20\%). Most of the patients received ATT on basis of pleural fluid cytochemistry and clinical judgment (70\%). There was one patient (1.6\%) who died after 3 days of hospitalization. Three patients (4.6\%) were referred to another hospital for surgical intervention. All of other patients were discharged on oral antibiotic or antitubercular drugs.

\section{Discussion}

Pleural effusion as a complication is a common problem in children because of high incidence of pneumonia and tuberculosis in our country. In this study we tried to found out different treatment modalities of pleural effusion and their outcomes. We found that boys were affected more as compared to girls which are probably due to male domination in our society. Bilateral pleural effusion was found in 9.4 percent of patients, which was similar to another study conducted by Bhatta NK and et. $\mathrm{al}^{8}$ who reported that right sided effusion was found in $59 \%$ and bilateral effusion in $7.7 \%$ of children. Initially all patients were treated with IV antibiotics (cefotaxime plus flucloxacillin or ampicillin-cloxacillin) as first line therapy. Treatment was modified to vancomycin with or without ceftazidime depending upon clinical improvement of the patients. Twelve $(18.2 \%)$ patients were treated with vancomycin. Culture positive effusion was found in four $(6.4 \%)$ patients only. Staphylococcus and Streptococcus were grown in two samples each. Bhatta $\mathrm{NK}^{8}$ reported $15 \%$ culture positive cases. 
Similar study done by Barnawal $\mathrm{AK}^{9}$, found that $93 \%$ of children were treated with parenteral cloxacillin and aminoglycoside along with chest tube drainage; in $92 \%$ of fibropurulent cases and was successful in $79 \%$. Of 48 patients with failed tube drainage, 12(4.9\%) needed decortication and four patients(1.6\%) died. In our study $59 \%$ patients were put on chest tube drainage, $4.6 \%$ of cases needed decortication and one patient(1.6\%) died durring hospital stay.

About $10 \%$ of childhood tuberculosis may develop pleural effusion ${ }^{10}$. However in the study conducted by Merino $\mathrm{JM},{ }^{11}$ they reported that occurance of pleural effusion in $22 \%$ of paediatric tuberculosis. In our study $30 \%$ patients were treated with anti-tubercular drugs along with antibiotics. Salesh $\mathrm{AB}^{12}$ and others found that $66 \%$ of paediatric pleural effusions were due to tubercular etiology. Adenine deaminase ( ADA) test of pleural fluid was done in only 4 patients out of which 2 were positive. Pleural fluid ADA has long been used as a marker for tuberculous pleurisy. Different studies have showed a positive ADA test of pleural fluid, with a sensitivity and specificity of 80 to $100 \%$ to make a diagnosis of tubercular pleural effusion ${ }^{13-15}$.

\section{Acknowledgement: None \\ Funding: None \\ Conflict of Interest: None}

\section{Conclusion}

In conclusion the most effective treatment for pleural effusion is parental antibiotic and close chest tube drainage. Anti-tuberculosis drug was also widely used in the management of pleural effusion. Diagnosis of tuberculer pleural effusion needs further study to reduce over use of anti-tubercular drug and development of drug resistance. It is better to do other confirmatory tests rather than use a therapeutic trial of anti-tubercular drug in pleural effusion. Pleural fluid ADA test may be a helpful test to diagnose tubercular effusion. This test is now available in our country and is not so expensive.

\section{References}

1. Crompton GK, Haslett C. Pleural effusion. In: Edwards CRW, Bouchier IAD, Haslett C, Chilvers ER. Davidson's Principle and Practice of Medicine, $17^{\text {th }}$ ed. Churchill Livingstone, $1995,396-399$.

2 Ori Efrati and Asher Barak. Pleural Effusion in the Pediatric population. Pediatric Review2002;23:417426.
3. Byington CL, Spencer LY, Johnson TA, Pavia AT, Allen D, Mason EO, Kaplan S, Carroll KC, Daly JA, Christenson JC and Samore MH. An epidemiological investigation of sustained high rate of paediatric empyema. Clinical Infectious Diseases 2002;34:434-40.

4. Srrang C. Pathogenesis and management of parapneumonic effusion and empyema. In Feigin RD (ed) UpToDate paediatrics. Wellesley, MA: UoToDate;2001.

5. Givan DC and Eigen H. Common pleural effusion in children. Clinical Chest med.1998;19:363-371.

6. Nepal Ministry of Health, Department of health services annual report. Kathmandu. 2000-2001.

7. Padmini RS, Srinivasan S, Puri RK and Nalini P. Empyema in infancy and childhood. Ind Pediatric 1990;27:447-452.

8. Bhatta NK, Sing AP, Kalakheti B, Shrestha P and Singh R. Clinical spectrum and outcome of empyema in Nepalese children. $J$ of Nepal Paediatric Society 2008;28(2), 49-51

9. Barnawal AK, Sing M, Marwaha RK and Kumar L. Empyema thoracis: A 10 year comparative review of hospitalized children from South Asia. Arch Dis Child 2003;88:1009-14.

10. Ghai O P. Tuberculosis in childhood. Essential Ped, $4^{\text {th }}$ ed, New Delhi 1996:161-163

11. Merino JM, Carpintero I, Alvarez T, Rodrigo J, Sanchez $\mathrm{J}$ and Coello JM. Tuberculous pleural effusion in children. Chest 1999 Jul; 115(1):26-30.

12. Salesh AB Memon and Shajeel J Shaikh. Etiology of pleural effusion in children: Hyderabad experience. Pak J Med Science 2007 Jul- Mar; 23(1):86-87.

13. Verma SK, Dubey AL, Sing PA Tewerson SL and Sharma D. ADA level in tubercular pleural effusion. Lung India 2008 Jul- Sep; 25(3):109-110.

14. Jiménez CD, Díaz Nuevo D, Pérez-Rodríguez $E$ and Light RW. Diagnostic value of adenosine deaminase in nontuberculous pleural effusion. Eur Respir J 2003;21:220-224

15. Mathur PC, Tiwary KK, Trikha S and Tiwary D. Diagnostic value of ADA activity in Tubercular serositis. Indian J tuberculosis 2006;53:92-95.

\section{How to cite this article?}

Shrestha PN, Rayamajhi A. Pleural Effusion in Children: How often do we suspect Tubercular origin? J Nep Paedtr Soc 2010;30(3):132-134. 